\title{
The Effect of Crown Ethers on Enzyme-catalysed Reactions in Organic Solvents
}

\author{
David N. Reinhoudt,*a Anke M. Eendebak, , Wilma F. Nijenhuis, a Willem Verboom,a Marcel Kloosterman,b and \\ Hans E. Schoemakerb \\ a Laboratory of Organic Chemistry, University of Twente, P.O. Box 217, 7500 AE Enschede, The Netherlands \\ b D.S.M. Research, Bio-organic Chemistry Section, P.O. Box 18,6160 MD Geleen, The Netherlands
}

Crown ethers considerably enhance the rate of the $\alpha$-chymotrypsin-catalysed transesterification of $\mathrm{N}$-acetyl-L-phenylalanine ethyl ester ( $\mathrm{N}$-Ac-L-Phe-OEt) with propan-1-ol in n-octane; with subtilisin the effect is somewhat less pronounced.

Recently, biocatalysis in organic apolar solvents has been successfully applied in stereoselective (trans)esterification reactions. $1-5$ The advantages of enzymic reactions in organic solvents are the solubility of the organic substrates, enhanced thermal stability of enzymes, and the elimination of undesired side-reactions that involve water as the nucleophile. ${ }^{1}$ Such reactions take place in heterogeneous systems and different methods to increase the rates of reaction have been reported. The first method involves immobilisation of the enzyme ${ }^{6}$ and the second comprises the covalent attachment of polyethylene glycol chains in order to increase the hydrophobicity of the enzyme surface. ${ }^{7}$

Macrocyclic polyethers are able to dissolve guanidinium, ${ }^{8}$

Table 1. Rate acceleration factors of the transesterification of $N$-Ac-L-Ph-OEt.a

\section{Macrocycle}

18-Crown-6

Dicyclohexyl-18-crown-6

Monoaza-18-crown-6

Dibenzo-18-crown-6

15-Crown-5

12-Crown-5

Diaza-18-crown-6

Dibenzo-24-crown-8

$\alpha$-Chymotrypsin
4.1
3.6
2.9
2.3
1.7
1.7
1.5
1.5

Subtilisin

2.0

1.9

1.7

1.0

0.9

0.9

1.2

0.8

a Reaction conditions: $1.0 \mathrm{M}$ propan-1-ol in n-octane; $5 \mathrm{~mm} \mathrm{~N}$-Ac-LPhe-OEt; $0.75 \mathrm{~mm}$ crown ether; $37^{\circ} \mathrm{C} ; 250 \mathrm{rpm} ; 1 \mathrm{mg}$ enzyme $/ \mathrm{ml}$. alkylammonium, ${ }^{9}$ and carboxylate ${ }^{10}$ salts via complexation of the cation. To the best of our knowledge only Odell and Earlam have studied the effect of macrocyclic polyethers on the solubility of proteins in methanol. $11 \mathrm{We}$ have investigated the effect of macrocyclic polyethers on enzyme-catalysed reactions in apolar organic solvents. The effect of a series of macrocyclic polyethers on the well-known transesterification of $N$-acetyl-L-phenylalanine ethyl ester ( $N$-Ac-L-Phe-OEt) with propan-1-ol in n-octane, catalysed by $\alpha$-chymotrypsin or subtilisin, has been studied. ${ }^{4} \dagger$ The rate acceleration factors $\ddagger$ after a reaction time of $6 \mathrm{~h} \S$ are summarised in Table 1 , performing the reaction under the same conditions as used by Zaks and Klibanov. ${ }^{4,5}$ The data in Table 1 show that in the case of $\alpha$-chymotrypsin all crown ethers accelerate the reaction. It should be emphasised that crown ethers do not catalyse the reaction in the absence of $\alpha$-chymotrypsin. As 18-crown-6 and dicyclohexyl-18-crown-6 show the largest acceleration, the kinetics of these reactions were studied. The Lineweaver-Burk plots of the reactions exhibit acceptable

$\dagger \alpha$-Chymotrypsin was purchased from Boehringer Mannheim (90 $\mathrm{U} / \mathrm{mg}$ ). Subtilisin was purchased from Sigma; protease from Bacillus subtilis $(10-15 \mathrm{U} / \mathrm{mg})$. Both enzymes were pretreated according to refs. 4,5 .

$\ddagger$ Rate acceleration factor $=$ conversion $(+$ crown ether $) /$ conversion (blank reaction). For the analysis, $5 \mu \mathrm{l}$ aliquots were withdrawn and assayed by gas chromatography using a capillary column (SE-54 Hewlett Packard).

$\S$ The rate acceleration factors were calculated from the conversion after a reaction time of 6 hours. 
Table 2. Kinetic parameters of the transesterification of $N$-Ac-L-PheOEt.a

\begin{tabular}{lcc}
\multicolumn{1}{c}{ Macrocycle } & $\alpha$-Chymotrypsin & Subtilisin \\
None & $0.8^{\mathrm{b}}$ & 0.6 \\
18-Crown-6 & 3.8 & 1.5 \\
Dicyclohexyl-18-crown-6 & 1.8 & 1.9
\end{tabular}

a Reaction conditions: $1.0 \mathrm{M}$ Propan-1-ol in n-octane; $0.5-50 \mathrm{~mm}$ $N$-Ac-L-Phe-OEt; $0.75 \mathrm{~mm}$ crown ether; $37^{\circ} \mathrm{C} ; 250 \mathrm{rpm} ; 1 \mathrm{mg}$ enzyme/ml. b The same value was obtained by Zaks and Klibanov. ${ }^{5}$

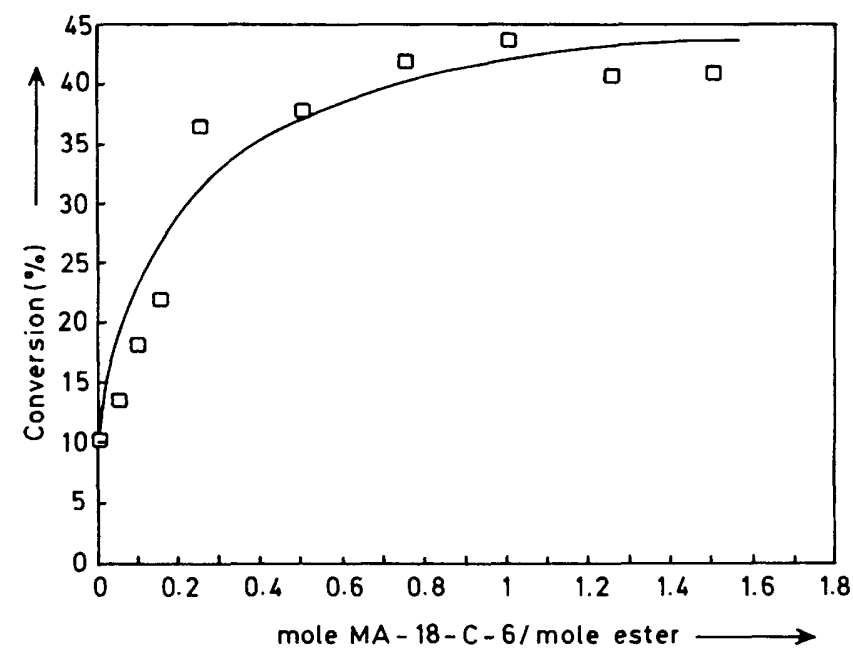

Figure 1. Effect of concentration MA-18-C-6. Reaction conditions: $1.0 \mathrm{M}$ propan-1-ol in n-octane; $5 \mathrm{~mm} N$-Ac-L-Phe-OEt; $0.75 \mathrm{~mm}$ crown ether; $37^{\circ} \mathrm{C} ; 250 \mathrm{rpm} ; 1 \mathrm{mg}$ enzyme $/ \mathrm{ml}$.

linear correlations between $1 / V_{0}$ and $1 / S_{0}$. This means that it can be assumed that the reactions follow Michaelis-Menten kinetics. The $V_{\max } / K_{\mathrm{M}}$ values were determined and compared with that of the reaction in the absence of crown ether (Table 2).

We have also studied the influence of the crown ether concentration. Figure 1 shows the influence of different concentrations of crown ether for the reaction with monoaza18-crown-6 (MA-18-C-6) as a particular example. A variation of the ratio crown ether/ester from 0 to 1.5 exhibits an increase of the conversion (measured after a reaction time of $1 \mathrm{~h}$ ) until at a ratio of about 1.0 , a maximum, is reached. This suggests that at that ratio saturation of the enzyme with crown ether is reached. For 18-crown-6 a similar pattern was observed.

With subtilisin as the enzyme, the rate acceleration factors (Table 1) and the $V_{\max } / K_{\mathrm{M}}$ values (Table 2) were also determined for the same crown ethers. In this case a similar accelerating effect was observed for a number of crown ethers.

At the moment we can only speculate about the reason for the crown ether induced rate acceleration. We could confirm that for good activity of the enzymes pretreatment with a potassium phosphate buffer is necessary. ${ }^{4,5}$ It might be that complexation of the ammonium, guanidinium, and potassium cations at the outside of the enzyme, by the crown ether added, renders the enzyme more soluble in the apolar solvent. $\uparrow$ When $\alpha$-chymotrypsin was pretreated with a lithium phosphate buffer of the same $\mathrm{pH}$ (7.8; the optimal $\mathrm{pH}$ of the enzyme) the conversion was much slower. The larger association of potassium for the 18 -membered rings might explain the larger rate enhancement. We can conclude that our method offers a very interesting and promising approach to accelerate biocatalysis in organic solvents.

Received, 21st October 1988; Com. 8/04187C

\section{References}

1 A. M. Klibanov, Chem. Tech., 1986, 16, 354.

2 J. S. Deetz and J. D. Rozzel, Tibtech, 1988, 6, 15.

3 G. M. Whitesides and C.-H. Wong, Angew. Chem., 1985, 97, 617.

4 A. Zaks and A. M. Klibanov, J. Am. Chem. Soc., 1986, 108, 2767.

5 A. Zaks and A. M. Klibanov, J. Biol. Chem., 1988, 263, 3194.

6 J. Grunwald, B. Wirz, M. P. Scollar, and A. M. Klibanov, J. Am. Chem. Soc., 1986, 108, 6732

7 Y. Inada, H. Nishimura, K. Takahashi, T. Yoshimoto, A. Ranjan Saha, and Y. Saito, Biochem. Biophys. Res. Commun., 1984, 122, 845 .

8 J. W. H. M. Uiterwijk, C. J. van Staveren, D. N. Reinhoudt, H. J. den Hertog Jr., L. Kruize, and S. Harkema, J. Org. Chem., 1986, 51, 1575.

9 J. A. A. de Boer and D. N. Reinhoudt, J. Am. Chem. Soc., 1985, $107,5347$.

10 W. L. Dorn, A. Knöchel, J. Oehler, and G. Rudolph, Z. Naturforsch., Teil B, 1977, 32, 776.

11 B. Odell and G. Earlam, J. Chem. Soc., Chem. Commun., 1985, 359.

I Using a concentration of $75 \mathrm{~mm}$ of MA-18-crown-6 in one experiment a clear solution was obtained. However, after a conversion of about $50 \%$ of the $N$-Ac-L-Phe-OEt, the $\alpha$-chymotrypsin precipitated. 